cians finally awakened to their patients' complaints; thus, an important medical observation was made.

The railroad signals-Stop, look, and listen-are excellent bywords for every physician to practice. They can admonish us of that oncoming "train"-illness or disease.

GEORGE W. NORTHUP, DO

Editor Emeritus

\section{PEF flow meter plays important role in asthma therapy}

Asthma, a hyperreactive airway disease, is characterized by inflammation, excessive mucus secretion, and bronchospasm that results in intermittent episodes of respiratory distress. Medication such as $\beta$-agonists, theophylline, and anti-inflammatory therapy-inhaled or systemic corticosteroids - can reverse this obstruction if it does not subside spontaneously.

Generally, asthma occurs at specific times during the day. Approximately $70 \%$ of patients have asthma-related sleep disturbance at least once a week even when they comply with their therapeutic regimen.

As the incidence, severity, and mortality of asthma appear to be on the rise, physicians are constantly searching for better ways of monitoring this disease. Primary care physicians, pulmonologists, and allergists recommend that patients use an inexpensive peak expiratory flow (PEF) meter to assess their own airway status. Lightweight and easy-touse, although somewhat bulky, the PEF meter affords an excellent means of evaluating pediatric or adult patients' airflow in the hospital or, more importantly, on an outpatient basis.

Patients require some minor instruction on how to use the device effectively. Additionally, they should be taught how to use metered- dose inhalers correctly, which are commonly used to deliver medication. Either the physician or a member of the office staff can instruct patients during their office visit. Patients should be told to use the PEF meter when they stand or sit upright. After taking a deep breath, patients should blow out as forcibly as possible in the shortest time. A nose clip is not necessary.

After each use, the device must be reset to zero. Patients should record the date and the highest numeric value of three consecutive PEF measurements in a notebook each time they use the device. In this way, diurnal and nocturnal asthma symptoms can be correlated with an actual flow measurement. Both the patient and the physician will better appreciate asthma's temporal dependencies.

Because asthma typically occurs or worsens at night, PEF has a rather prominent circadian rhythm. Persons who are active during the day and sleep at night tend to have their best PEF measurement around midday, while their worst PEF measurement occurs in the early morning hours, around $4 \mathrm{AM}$. Conversely, the asthmatic individual who works nights, for example, and sleeps during the day generally experiences difficulty breathing during daytime sleep.

Persons with normal pulmonary function have a high mean 24-hour airflow within the range of predicted values for persons of corresponding age and body build. Moreover, the day-night variability in airflow remains minimal, with generally no more than $10 \%$ of the 24-hour mean level.

Among asthma patients, however, the mean daily PEF is often reduced considerably from that of normal peak reference values; the circadian variability is enhanced. Generally, the daily mean PEF declines and circadian variability increases as the airways become unstable with a worsening of the disease.

(continued on page 860 ) 


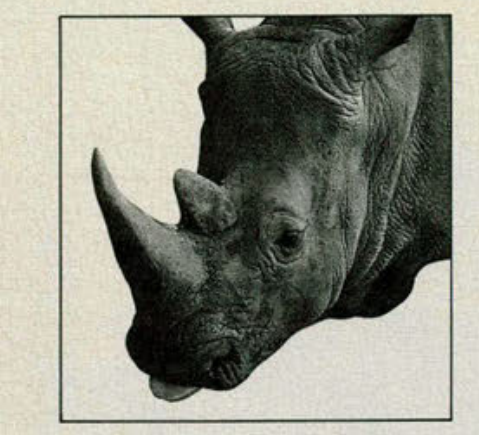

\section{It's on its way to your office.}

\section{BROMFED Timed-release Capsules (brompheniramine maleate $12 \mathrm{mg}$ and} pseudoephedrine $\mathrm{HCl} 120 \mathrm{mg}$ )

BROMFED-PD ${ }^{\circledR}$ Timed-release Capsules (brompheniramine maleate $6 \mathrm{mg}$ and pseudoephedrine $\mathrm{HCl} 60 \mathrm{mg}$ )

\section{Brief Summary}

CONTRAINDICATIONS Hypersensitivity to any of the ingredients. Also contraindicated in patients with severe hypertension, severe coronary artery disease, patients on MAO inhibitor therapy, patients with narrow-angle glaucoma, urinary retention, peptic ulcer and during an asthmatic attack.

WARNINGS Considerable caution should be exercised in patients with hypertension, diabetes mellitus, ischemic pressure and prostatic hypertrophy. The elderly (60 years or pressure and prostatic hypertrophy. The elderly 60
older) are more likely to exhibit adverse reactions

Antihistamines may cause excitability, especially in children. At dosages higher than the recommended dose, nervousness, dizziness or sleeplessness may occur

PRECAUTIONS General: Caution should be exercised in patients with high blood pressure, heart disease, diabetes or thyroid disease. The antihistamine in this product may exhibit additive effects with other CNS depressants. including alcohol.

Information for Patients: Antihistamines may cause drowsiness and ambulatory patients who operate machinery or motor vehicles should be cautioned accordingly.

Drug Interactions: MAO inhibitors and beta adrenergic blockers increase the effects of sympathomimetics. Sym pathomimetics may reduce the antihypertensive effects of methyldopa, mecamylamine, reserpine and veratrum alkaloids. Concomitant use of antihistamines with alcohol and other CNS depressants may have an additive effect.

Pregnancy: The safety of use of this product in pregnancy has not been established.

ADVERSE REACTIONS Adverse reactions include drowsiness, lassitude, nausea, giddiness, dryness of the mouth, blurred vision, cardiac palpitations, flushing, in creased irritability or excitement (especially in children).

Dosage and Administration

BROMFED* CAPSULES Adults and children over 12 years of age: 1 capsule every 12 hours.

BROMFED-PD* CAPSULES Children 6 to 12 years of age: 1 capsule every 12 hours. Adults and children over of age: 1 capsule every 12 hours. Adults and child
12 years of age: 1 or 2 capsules every 12 hours.

BROMFED* TABLETS Adults and children 12 and over: One tablet every 4 hours not to exceed 6 doses in 24 hours. Children 6 to 12 years: One-haif tablet every 4 hours not to exceed 6 doses in 24 hours. Do not give to children under 6 years except under the advice and supervision of a physician.

CAUTION: FEDERAL (U.S.A) LAW PROHIBITS DISPENSING WITHOUT A PRESCRIPTION.

\section{Distributed by}

\section{Muro}

Pharmaceutical, Inc.

Tewksbury, MA 01876-9987

\section{editorials}

(continued)

Some physicians advise their patients to assess their PEF twice daily, such as in the morning on arising and in the evening before bedtime. For a more complete evaluation of airway status, other practitioners prefer that their patients take measurements three or more times a day-in the morning on arising, midafternoon, and just before retiring.

When persons have an asthma attack at night, they should take an additional airflow measurement before taking any bronchodilator medication. Sometimes it is helpful for the asthma sufferer to assess PEF before and $a f$ ter the use of bronchodilator medication. In this way, the physician can monitor suitable intervention strategies for treating acute asthma. Generally, patients who consistently assess PEF measurements can better predictand hence preempt-asthma attacks. With proper medical supervision and training beforehand, patients can take appropriate medical therapeutic action while they seek further medical advice.

Peak expiratory flow monitoring enables both patients and physicians to understand the natural history and course of this disease. With this knowledge, including the individual patient's response to and need for additional pharmacotherapy, physicians can avert serious bouts of asthma-and perhaps even death-in our asthmatic patient population atlarge.

\author{
GILBERT E. D'ALONZO, DO \\ JAOA Contributing Editor \\ Associate Professor \\ School of Medicine \\ University of Texas Health Science \\ Center at Houston \\ Houston, Tex \\ MICHAEL H. SMOLENSKY, PhD \\ Professor \\ School of Public Health \\ University of Texas Health Science \\ Center at Houston \\ Houston, Tex
}




\section{It's 6 AM. \\ Do You Know Where Your Patients' NSAIDs Are?}

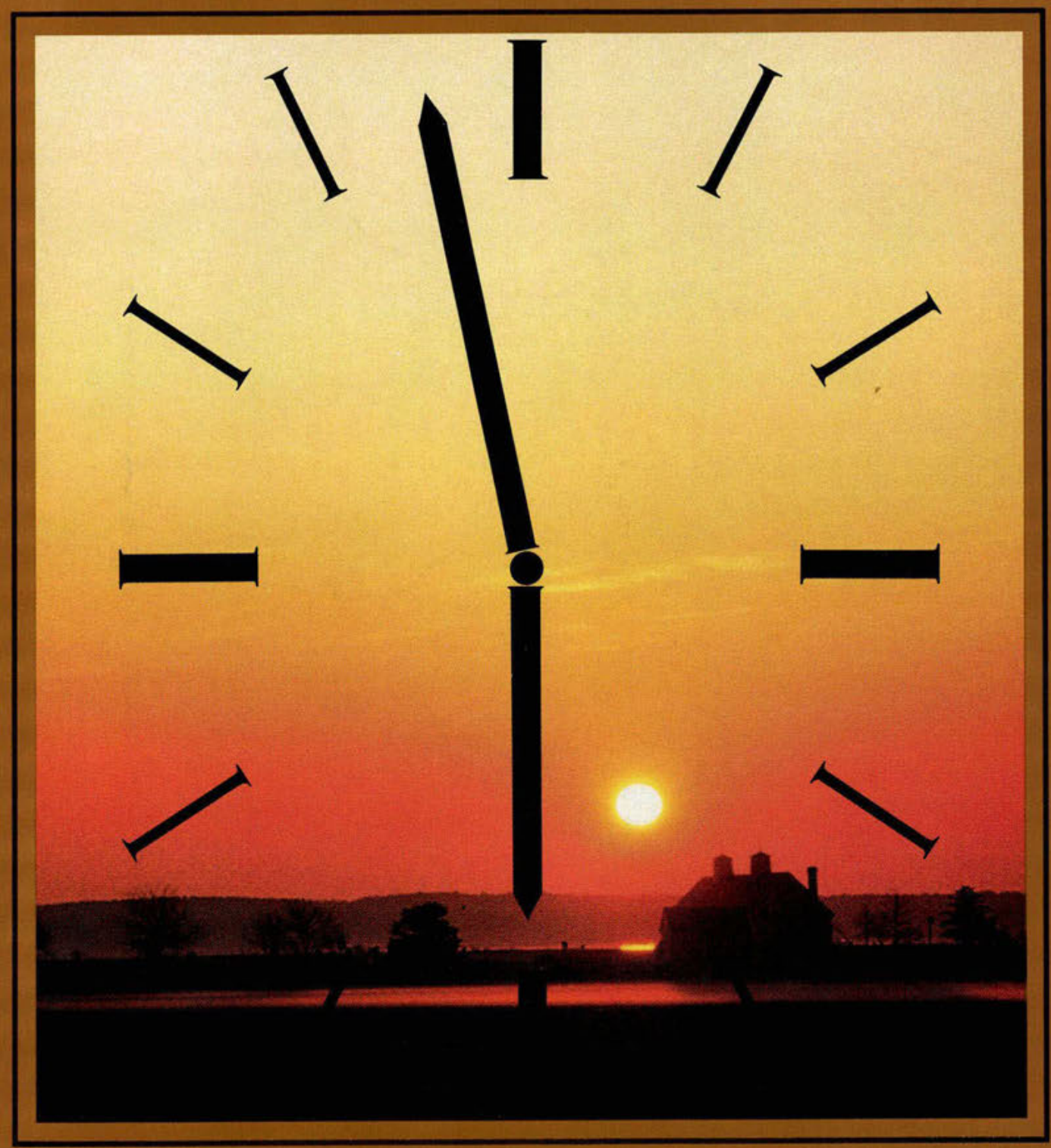

You Know When You

Prescribe Once-Daily Feldene

Well-Tolerated, Around-the-Clock Arthritis Therapy 


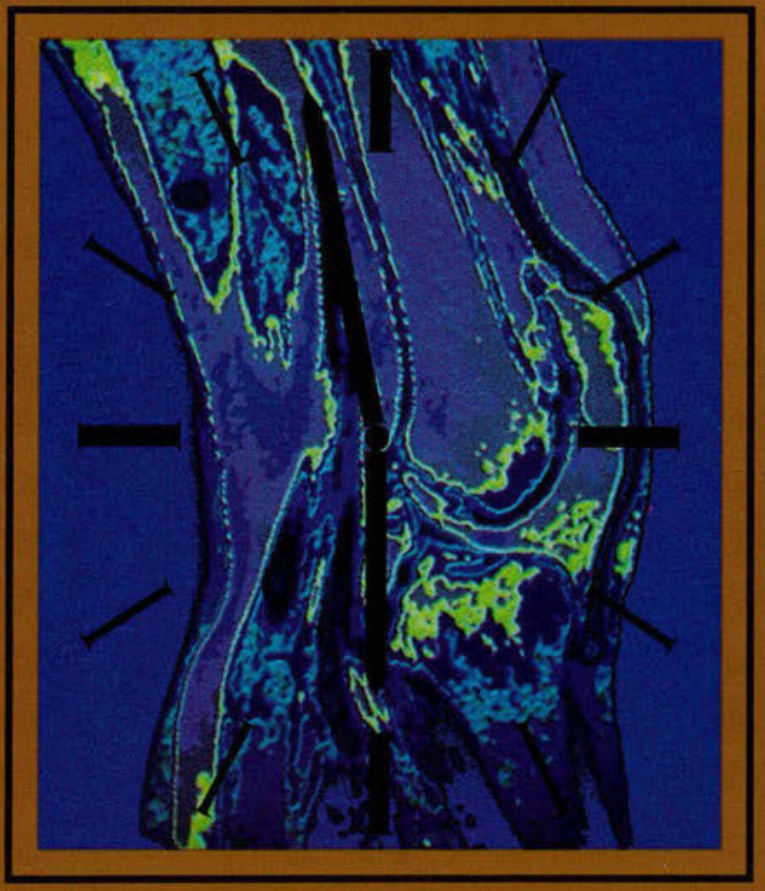

\section{Once-Daily}

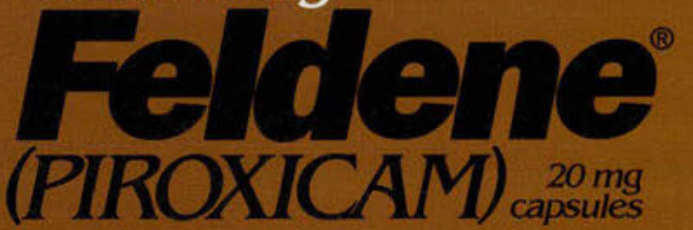

\section{Well-Tolerated, Around-the-Clock Arthritis Therapy}

As with other NSAIDs, GI-related side effects may occur in some patients: these include ulceration, bleeding, and perforation.

FEDERE" (piroxicam) Caprules

COWTRANDICATIONS: FEL OENE (Diroxicam) should not be used in patents who have previously exhibited hypersensitivity to it, or in indwiduals with the syndrome comprised ot bronchospasm, nasal polyps and angivedema preciptated by aspirin or other nonsteroidal anti-inflammatory drugs

WAFWINGS: Pegtic ulceration, perforation, and G I bieeding-sometimes severe, and, in some instances tatal-have been reported with patients receiving FEL OENE. If FELDENE must be given to patients with a history of upper gastrointestinat
tract disease, the patient should be under close Supervision (sef ADVFASE REACTIONS) Physicians sheuld remain alen tract disease, the patient should be under close supervision (see ADVERSE REACTONS). Physicians should remain aler:
for uiceration and bleeding in patients treated chronically with NSAIDs even in the absence of previous Git tract symo

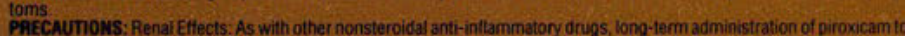
animals has resulted in renal Papiliary necrosis and other abnormat renal Pathology, In humans, there have been reports of acute interstutua nephrtits wen nematura, proteinuna, and occasionaly, nephrocic symurome

A second form of renal toxicity has been seen in patients with prefenal conditions leading to a reduction in renal blood flow or blood volume, where the renal prostaglandins have a supportive role in the maintenance of renal pertusion in thess patients administration of an NSAID may cause a dose-dependent reduction in prostaplandin formation and may precipitate
overt renal decompensation. Patients at oreatest risk of this reaction are those with inpaired renal function. heart lailuce. overt renal oecompensation Patients at greatest nsk
liver dystunction. those taking diuretics. and the elderly

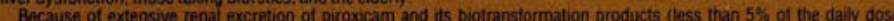
excreted unchanned) lower doces of nirrexicam should be anticinated in patients with impained renal function and the sthould be carafully monitored

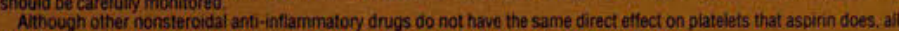
drugs inhibiting prostaglandin biosynthesis do interfere with platelet function to some degree.

Because of reports of adverse eye findinos with nonsteroidal anti-inflammatory agents, it is recommended that patients who develop visual complaints during treatment with FEL DENE have ophthalmic evaluation

As with other nonsteroidal anti-inflammatory drugs, borderline elevations of one or more liver tests may occur in up to $15 \%$ of patients. A patient with symptoms and or signs suggestino liver dystunction, or in whom abnormal fiver tests have occurred, should be evaluated for evidence of the developinemt of more severe hepatic reaction while on therapy witt

Severe hepatic reactions, including jaundice and cases of fatal hepatitis, have been reported with FEL DENE. Athough such reactions are rare, if abnormal liver tests persist or worsen. it clinical signs and symptoms consistent with liver disease develop, or if systemic m

Although at the recommended dose of 20 mgd day of FELDENE increased tecal blood loss due to gastrointestinal irritation did aot occur, in about 496 of the patients freate

hemoglobin and hematocrit values were observed.
Perioheral edema has been observed in approximately $2 \%$ of the patients treated with FEL DENE. Therefore. FELDENE should be used with caution in patients with heart fallure, hypertension or other conditions predisposing to fluid reten. tion

A combination of dermatological and/or allergic sions and symptoms suggestive of serum sickness have occasionally occurred in conjunction with the use of FEL DEVE. These include arthralgias, prurtus. fever, tatigue, and rash including

vesiculo bullous reactions and extoliative dermatitis
DRUG INTERACTIONS: Interactions with coumarin-type anticoagutants have been reported with FELDENE since marketing. Therefore. physicians should closely monitor patients for a change in dosage req
oatients on coumarin-type anticoapulants and other highily protein-bound drugs

patients on coumarin-type anticosgulants and other highty protein-bound drugs Plasma leveis of piroxicam are depressed to approximately $80 \%$ of their normai values when FELEENE is administered in
conjunction with aspirin ( $3900 \mathrm{mg} /$ day), but concornitant adrninistration of antacids has no effect on piroxicam plasma lev ils

Nonsteroidal anti-inflammatory agents, including FEL DENE, have been reported to increase steady state plasma lithium Carcinogenests, Chronic Animal Toxicity and impaiment of Fertility: Subacute and chronic toxicity studies have been carried out in rats, mice dons and monkays,

The pathology most often seen was that characteristically associated with the animal toxicology of anti-infiammatory agents. renal paoiliary necrosis (see PRECAUTIONS) and gastrointestinal lesions

In classical studies in laboratory animals, piroxicam did not show any teratogenic potentia

Reproductive studies revealed no impaiment of tertility in animals.
Presgnancy and Mursing Mothers: Like other drugs which inhibit the synthesis and release of prostaglandins, piroxicam administration continued late into pregnancy increased the incidence of dystocia and delayed parturition in animals. Gas.
trointestinal tract toxicity was increased in preonant females in the last trimester of oregnancy compared to non-pregnant trointestinal tract toxicity was increased in pregnant $f$
females or females in earlier trimesters of pregnarcy.

FELDENE (piroxicam) is not recommended for use in nursing mothers or in pregnant women because of the anima

ngs and since satety for such use has not been established in humans
Use in Children: Dosage recommendations and indications for use in children have not been established OVERSE REACTIONS: Gastrointestinat symptoms are the most prominent side effects, occurring in approximately 2 the patients. Which in most instances did not intertere with the course of therapy of the patients experiencing gastroi

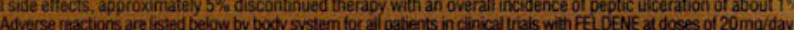

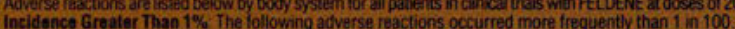

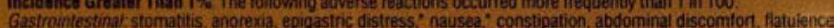
thea, abdominal pain, indigestion

Hernatological decreases in hemoglobin" and hernatocnt" (see PBECAUTIONS), anemia, leucopenia, eosinophilis Dermatologic pruritus, rash

Central Nervous System dazziness, somnolence, vertigo
Urogenital: BUN and creatinine elevations isee PRECAlTIONS)

Urogenital BUN and creatinine elevations
Body as a Whole headache, malaise

Body as a Whole headar
Special Senses, tinnitus

Special Senses: tinnitus

- Reactions occurring in $3 \%$ to $9 \%$ of patients treated with FELDENE, Reactions occurning in $1 \%$ to $3 \%$ of patie nmarkid

Incidence Less Than 1\% (Causal Relationship Probabie): The following adverse reactions occurred less frequently 100 The probability exists that there is a causal relationship between FELDENE and these reactions

Gastrointestinat liver function abnormalities, jaundice, hepatitis (see PRECAU)
gastrointestinal bleeding. perforation and ulceration (see WARNINGS), dry mout:

Hematological : thrombocytopenia, Detechiaf rash, ecchymosis, bone marrow depression including aplastic anemia Dermatologic sweating, erythema, bruising, desquamation, exdoliative dermatutis, erythema multiforme, toxic epic ecrotysis. Stevens Johnson syndrome, vesiculo bullous reactions, photoaliergic skin reactions

Central Nervous System depression, insomnia nervousnes:

Urogenital hematuria, proteinuria, interstitial nephritis, renal failure, hyperkalemia, olomenultis, papillary nec

Body as a Whole pain (colic). lever, flu-like syndrome (see PRECAUTrONS)

Gardiovascular:Respiratory hypertension, worsening of congestive heart fature (see PRECAUTiONS), exacerbat angina

Metabolic: hypoglycemia hyperglycemia, weight increase, weight decrease

Hypersensitivity anaphylaxis, bronchospasm, urticaria/angioederna, vasculitis, "serum sickness" (see PRECAUnC Incidence Less Than $1 \%$ (Causal Relationship Uniknown): Other adverse reactions were reported with a frequency, than 1 in 100 , but a causal relationship between FELDENE and the reaction could not be determined

Castrumtestinat pancitains

Dermatologic onychiolysis, loss of hair

Centrai Nervous System: akathisia, hailucinations, mood alterations, dream abnormalities, mental confusion, paresti Urogenital System dysuria

\section{cooy as a Whoie weakness}

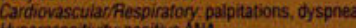

pecial Senses transient heario

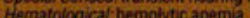

OVERDOSAGE: In the event treatment for overdosage is required, the long plasma hall-ble of piroxicam should be c ered. The absence of experience with acute overdosage prectudes characterization of sequelae and recommendat specitic antidotal efficacy at this time. It is reasonable to assume that the standard measures of gastric evacuation an erat supportive therapy would apply - in addition to supportive measures, the use of activated charcoal may effectively the absorption and reabsorption of piroxicam. Expenments in dogs have demonstrated that the use of multiple-dose

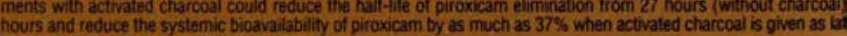
hours after administration of piroxicas

ADMiNISTAATION AND DOSAGE: Fheumatoid arthritis, Osteoarthritis: It is recommended that FELDENE therapy be ed and maintained at a single dally dose of $20 \mathrm{mg}$ if desired, the daily dose may be divider.

Oosage recommendations and indications for use in chidren
More detailed professional information avallable on repuest 